\title{
Combined Instrumentation Package COMARS+ for the ExoMars Schiaparelli Lander
}

\author{
Ali Gülhan, Thomas Thiele, Frank Siebe, Rolf Kronen \\ Deutsches Zentrum für Luft- und Raumfahrt (DLR) \\ $+4922036012363$ \\ $+4922036012085$ \\ ali.guelhan@dlr.de \\ http://www.dlr.de/as/hyp
}

\section{Abstract}

In order to measure aerothermal parameters on the back cover of the ExoMars Schiaparelli lander the instrumentation package COMARS + was developed by DLR. Consisting of three combined aerothermal sensors, one broadband radiometer sensor and an electronic box the payload provides important data for future missions. The aerothermal sensors called COMARS combine four discrete sensors measuring static pressure, total heat flux, temperature and radiative heat flux at two specific spectral bands. The infrared radiation in a broadband spectral range is measured by the separate broadband radiometer sensor. The electronic box of the payload is used for amplification, conditioning and multiplexing of the sensor signals. The design of the payload was mainly carried out using numerical tools including structural analyses, to simulate the main mechanical loads which occur during launch and stage separation, and thermal analyses to simulate the temperature environment during cruise phase and Mars entry. To validate the design an extensive qualification test campaign was conducted on a set of qualification models. The tests included vibration and shock tests to simulate launch loads and stage separation shocks. Thermal tests under vacuum condition were performed to simulate the thermal environment of the capsule during the different flight phases. Furthermore electromagnetic compatibility tests were conducted to check that the payload is compatible with the electromagnetic environment of the capsule and does not emit electromagnetic energy that could cause electromagnetic interference in other devices. For the sensor heads located 
on the ExoMars back cover radiation tests were carried out to verify their radiation hardness. Finally the bioburden reduction process was demonstrated on the qualification hardware to show the compliance with the planetary protection requirements. To test the actual heat flux, pressure and infrared radiation measurement under representative conditions, aerothermal tests were performed in an arc-heated wind tunnel facility. After all qualification tests were passed successfully, the acceptance test campaign for the flight hardware at acceptance level included the same tests than the qualification campaign except shock, radiation hardness and aerothermal tests. After passing all acceptance tests, the COMARS + flight hardware was integrated into the Schiaparelli capsule in January 2015 at the ExoMars integration site at Thales Alenia Space in Turin. Although the landing of Schiaparelli failed, resulting in the loss of most COMARS + flight data because they were stored on the lander, some data points were directly transmitted to the orbiter at low sampling rate during the entry phase. These data indicate that all COMARS + sensors delivered useful data until parachute deployment with the exception of the plasma black-out phase. Since measured structure and sensor housing temperatures are far below predicted preflight values, a new calibration using COMARS + spare sensors at temperatures below $0^{\circ} \mathrm{C}$ is necessary. Therefore no flight data is presented in this paper.

\section{Keywords}

Combined sensor package, entry phase, aerothermal heating, radiation, surface temperature, surface pressure, ExoMars, COMARS, heat flux, back cover, TPS, heat shield, Mars

\section{Abbreviations}

ARAD: Analog Resistance Ablation Detectors

CFD: Computational Fluid Dynamics

CNES: French Space Agency

COMARS: Combined Aerothermal and Radiometer Sensor

DHMR: Dry Heat Microbial Reduction

DLR: Deutsches Zentrum für Luft- und Raumfahrt

ECSS: European Cooperation for Space Standardization 
EDL: Entry, Descent, Landing

EDM: Entry Descent Module

EMC: Electromagnetic Compatibility

ESA: European Space Agency

FADS: Flush Airdata Sensing

FEM: Finite Element Method

FTIR: Fourier Transformed Infrared Spectrometer

HEAT: Hollow Aerothermal Ablation and Temperature

HFS: Heat Flux Sensor

ICOTOM: Narrow Band Infrared Radiometer of CNES

L2K: Arc heated wind tunnel facility of DLR

MEADS: Mars Entry Atmospheric Data System

MEDLI: Mars Science Laboratory Entry, Descent, and Landing Instrumentation

MISP: MEDLI Integrated Sensor Plug

MSC: Multiplexing Signal Conditioner

MSL: Mars Science Laboratory

PCB: Printed Circuit Board

PICA: Phenolic Impregnated Carbon Ablator

PSD: Power Spectral Density

RAD: Broadband Radiometer of COMARS+ payload

RTS: Resistance Temperature Sensing Element

SHEFEX: Sharp-Edge Flight Experiment

SIRCA: Silicone Impregnated Reusable Ceramic Ablator

TAS-I: Thales Alenia Space Italy

TGO: Trace Gas Orbiter

TPS: Thermal Protection System 


\section{INTRODUCTION}

The first mission of the ExoMars program which arrived at Mars in October 2016, consisted of a Trace Gas Orbiter (TGO) plus an Entry, Descent and Landing Demonstrator Module (EDM) named Schiaparelli. The orbiter and Schiaparelli were launched on 14th March 2016 on a Proton rocket. The main scientific objectives of this mission are to search for evidence of methane and other trace atmospheric gases that could be signatures of active biological or geological processes and to test key technologies in preparation for ESA's contribution to subsequent missions to Mars. Another important objective is the demonstration of a successful entry, descent and landing on Mars. Gathering scientific data during these flight phases is a further key element and would provide very important data for future missions. This data could be used for an optimization of the heat shield, as for example the design of the back cover heat shield was carried out with relatively high safety margins. This is due to the fact that the prediction of the aerothermal and radiative loads on the back cover, using existing experimental and numerical tools, still has big uncertainties.

The first successful mission to Mars including TPS instrumentation was Viking Lander 1 launched in 1975. The pre-flight prediction of the Viking afterbody heating, including a safety factor of 1.5 , estimated a value of $3 \%$ of the nose laminar heating for the backshell [1][2]. But the Viking post-flight analysis of the temperature data showed that a value of $4.2 \%$ was reached. It has to be mentioned that Viking Lander 1 was only instrumented with thin-film gauges at two locations on the back cover which were spot-welded to aluminum and fiberglass base covers. A heat flux rate of $9.7 \mathrm{~kW} / \mathrm{m}^{2}$ was derived from the thermocouple data on the aluminum structure at the time of sensor failure. On the fiberglass cover the sensor worked during the complete entry and a peak heating value of 6.6 $\mathrm{kW} / \mathrm{m}^{2}$ was determined [2]. A very interesting finding of this study is the delayed peak heating on the back cover compared to the front shell peak heating. But there is no clear explanation of this behavior.

Very high heat fluxes on the TPS occurred during the Galileo probe entry into the Jovian atmosphere in 1995. The heat shield of the Galileo probe which entered the atmosphere with a relative velocity of $47.4 \mathrm{~km} / \mathrm{s}$ was exposed to severe heat fluxes up to $170 \mathrm{MW} / \mathrm{m}^{2}$. To measure the TPS recession the capsule was instrumented with Analog Resistance Ablation Detectors (ARAD) and four 
thermometers [3]. Two thermometers were placed on the back cover and used to predict the rear surface recession based on the front surface recession measured by the ARAD sensors. Because of uncertainties in the front shield data, it was difficult to assess the afterbody heating.

A further successful Mars landing was performed by Mars Pathfinder in 1997 including the first Mars rover. The afterbody frustum of the Mars Pathfinder vehicle was coated with SLA-561S (a spray-on version of SLA-561V). The backshell interface plate and the rear portion of the frustum were covered with SIRCA (Silicone Impregnated Reusable Ceramic Ablator) tiles and had no surface-mounted instrumentation. But the aeroshell did contain nine thermocouples at various depths in the TPS material and three platinum resistance thermometers [4]. Unfortunately some thermocouples failed to provide useable data. For one near-surface thermocouple on the backshell the peak temperature could be matched to the predicted turbulent corner heating scaled by 0.026 , but with an incorrect shape of the thermocouple response.

In general the design of the entry capsule is carried out using numerical tools and ground experiments. The aerothermal design and sizing of the TPS of such capsules are carried out using Computational Fluid Dynamics (CFD) codes and ablative material response tools, which are supported by ground experiments. For the design margin of spacecraft structures the reliability of these design tools is essential. Since the physical models in numerical tools can only be validated partially, the design ends at high safety margins, i.e. high mass in the vehicle design. Assumptions like supercatalytic wall, fully turbulent flow environment, strong roughness induced heat flux augmentation, etc. lead to more than $40 \%$ extra forebody TPS thickness [5][6], which in turn has a significant impact on the overall mass budget.

Based on this fact the heat shield of the Mars Science Laboratory (MSL), which was launched in 2011 and successfully landed on Mars in 2012, was instrumented with several sensors to acquire important flight data for aerodynamics, aerothermal heating and performance of the TPS [7][8]. The installed MSL sensor package MEDLI (Mars Science Laboratory Entry, Descent, and Landing Instrumentation) allowed collecting pressure, temperature and recession data on the front TPS shield [9]. 
The MEDLI unit comprises sensors for surface pressure measurements called the Mars Entry Atmospheric Data System (MEADS) and a second instrumentation block for thermal performance (temperature and ablation tracking) of the heat shield called MEDLI Integrated Sensor Plugs (MISP). The MEADS part contains a Flush Airdata Sensing (FADS) system which collects aerodynamic data during flight. The pressure ports are arranged in such a way that aerodynamic parameters (e.g. angle of attack) can be computed from measured pressure values. In addition the measured pressure data allows verification of the trajectory reconstruction algorithm for MSL [10][11]. The MISP is a cylindrical embedded PICA plug with four type-K (chromel-alumel) thermocouples in different depts. In addition to the thermocouples an isotherm following sensor called Hollow aErothermal Ablation and Temperature (HEAT) is also installed in the plug to track the ablation process. In total seven MISP plugs were installed on the MSL front heat shield and no plugs were installed in the backshell of the vehicle. During Mars entry the MISP temperature data showed the occurrence of boundary-layer transition on the leeward side of the MSL forebody. The data also indicate that the thermal protection system recession was below predicted values.

To determine the overall performance and for trajectory reconstruction the Schiaparelli capsule of the ESA ExoMars 2016 mission was instrumented with four pressure sensors and seven thermal plugs in the front shield [12]. During former missions investigations concerning TPS heating were mainly focused on the front shield part due to the higher heat loads and less attention was paid to the heat loads on the back cover. An overview of afterbody aeroheating flight data for planetary entry probes is given in the paper of Wright et al. [13]. This paper recommends that for the reduction of mass and risk future planetary entry vehicles should include heat-shield instrumentation. The aftshell is suggested as the safest place to incorporate instrumentation because of the low heating rates.

In contrast to the MSL instrumentation, the Schiaparelli capsule also included several sensors on the back cover. In this region the Reynolds number of the flow is low and the flow itself has a highly transient character which results in comparatively low convective heat fluxes. But the radiative heat flux, mainly resulting from excitation of carbon dioxide molecules behind the strong bow shock, can be higher, exceeding the convective heat load. But neither ground test 
facilities nor numerical tools can simulate this radiation environment accurately. In order to close this gap, the Supersonic and Hypersonic Technology Department of the German Aerospace Center (DLR) in Cologne developed the combined aerothermal sensor package COMARS+, based on experience gathered during the flight instrumentation for the flight experiments SHEFEX-I and SHEFEX-II [14][15]. The COMARS + instrumentation package consists of three combined aerothermal sensors (called COMARS sensors), one broadband radiometer sensor and an electronic box [16]. The aerothermal sensors combine four discrete sensors measuring static pressure, total heat flux, temperature and radiative heat flux at two specific spectral bands. The infrared radiation in a broadband spectral range is measured by the separate broadband radiometer sensor. The electrical interface between sensors and Schiaparelli data handling system is provided by the payload electronic box.

This paper describes the main properties of the COMARS+ payload, mechanical and thermal design details and finally the results of aerothermal tests performed in the arc heated facility L2K at DLR Cologne. 


\section{REQUIREMENTS, DESIGN APPROACH AND MODEL PHILOSOPHY}

As mentioned above the prediction of aeothermal loads on the back cover of entry capsules has big uncertainties and ground testing cannot cover the complete entry environment. Therefore flight data is essential to reduce design margins and improve design tools. But in the past most capsules for planetary missions only had limited instrumentation. In particular the back cover was only instrumented with a minor number of sensors compared to the front shield, although this part of the vehicle also has a significant mass impact. To close this gap the COMARS+ instrumentation package was proposed for the Schiaparelli capsule back cover of the ExoMars 2016 mission. ESA defined a large compliance matrix of requirements for the acceptance of the COMARS + payload. The main constraints are given below:

- COMARS+ may not cause any risk to the success of the mission.

- The total mass of the payload should be less than $2 \mathrm{~kg}$ including maturity margins.

- The dimensions shall be as small as possible considering the required fixation points and available envelope.

- The average power consumption should stay below $7 \mathrm{~W}$ using an operative voltage between 22 and 36 Volt.

- Qualification tests, acceptance tests and documentation should be performed according to ECSS norm.

These requirements forced DLR to significantly adapt the SHEFEX sensor design and miniaturize sensor heads and electronics. During the design phase several thermal and mechanical analyses were performed for verification of the chosen design. Two sets of engineering models were manufactured to verify the preliminary design and general functionality of the components. For the qualification tests a set of qualification models (one COMARS sensor, one broadband radiometer sensor and one electronic box) was manufactured and subjected to mechanical, thermal/vacuum, shock, radiation hardness, electromagnetic compatibility and aerothermal tests at conditions defined by ESA and TAS-I in the applicable requirement documents. In addition to these tests, the 
cleaning procedure for the planetary protection requirements was tested on the qualification models to demonstrate that the number of spores could be reduced to the necessary level. One set of flight models was manufactured (three COMARS sensors, one broadband radiometer sensor and one electronic box) for the integration into the Schiaparelli capsule. In addition to the flight models a spare part for each individual component was made (one COMARS sensor, one broadband radiometer and one electronic box).

The ExoMars EDM mission (2016) was classified as Planetary Protection Category IVa, being a landed system not carrying life-detection experiments nor accessing a "special region" of Mars. The bioburden constraints for COMARS+ at delivery were defined as:

- Bioburden $\leq 1000$ bacterial spores on COMARS+ accountable exposed internal and external surfaces.

- Average bioburden density $\leq 300$ bacterial spores/m2 on the COMARS+ accountable exposed internal and external surfaces.

- All COMARS+ harness, including for H/W isolated by H14 equivalent HEPA filters, shall be processed with DHMR using six D-values for encapsulated bioburden.

- The encapsulated spores for COMARS+ payload shall be less than 13200 .

To satisfy these requirements all flight and spare components were assembled in a clean room environment and subjected to a bioburden reduction process. 


\section{PAYLOAD LAYOUT}

In comparison to the instrumentation for the Earth re-entry missions SHEFEX-I and SHEFEX-II, the sensor design for the COMARS sensor had to be adapted significantly. First of all the sensor interface with the TPS was redesigned to account for different TPS thickness, fixation method, available space and temperature environment. To keep the mass as low as possible, the interface was manufactured from titanium instead of stainless steel. Due to the very low pressure and limited space a different pressure sensor was used. A good compromise was found in a Pirani type pressure sensor which is small and able to measure very low pressures down to a few Pascal. To measure total heat flux and surface temperature, the cabling of the commercial heat flux microsensor used for SHEFEX-II was slightly adapted to fit into the new sensor interface. Furthermore the sensor interface was extended to incorporate two radiometers which measure the radiative heat flux at two specific spectral bands. These radiometers called ICOTOM were contributed by the French space agency CNES.

The infrared radiation in a broadband spectral range was measured by a separate broadband radiometer sensor which was developed for the ExoMars mission. It consists of a thermopile sensor integrated into a titanium sensor interface. To minimize the number of different mechanical interfaces at the back cover, outer dimensions and fixation points of the broadband radiometer interface are identical to the COMARS sensor.

The following table presents an overview of the different parts of the DLR ExoMars EDM back cover instrumentation.

Table 1: COMARS+ payload overview.

\begin{tabular}{|c|c|}
\hline Unit name & Description \\
\hline $\begin{array}{l}\text { Multiplexing Signal } \\
\text { Conditioner (MSC) }\end{array}$ & Electronic box \\
\hline COMARS1 (COM 1) & \multirow{3}{*}{$\begin{array}{l}\text { Combined static pressure, total } \\
\text { heat-flux, temperature and two } \\
\text { CNES spectral radiometer sensors } \\
\text { (ICOTOM) }\end{array}$} \\
\hline COMARS2 (COM 2) & \\
\hline COMARS3 (COM 3) & \\
\hline Radiometer (RAD) & Broadband radiometer \\
\hline Payload harness & $\begin{array}{l}\text { Harness connecting the } \\
\text { sensors to the electronic box }\end{array}$ \\
\hline
\end{tabular}


For the complete payload overall 23 sensor and 8 housekeeping signals have to be amplified to a specified input voltage range and multiplexed to three analogue acquisition channels of the EDM data handling system. This is done using an electronic box which is also part of the payload. In addition to amplification and multiplexing, a sensor signal conditioning is also integrated in the electronic layout. The actual digitization of the sensor signals is done by the capsule onboard data handling system and was not part of the COMARS+ payload. The analogue sensor signals were digitized with a 16 bit resolution and a sampling frequency of $10 \mathrm{~Hz}$. The location of the three COMARS sensors and the broadband radiometer on the Schiaparelli back cover is shown in Figure 1.

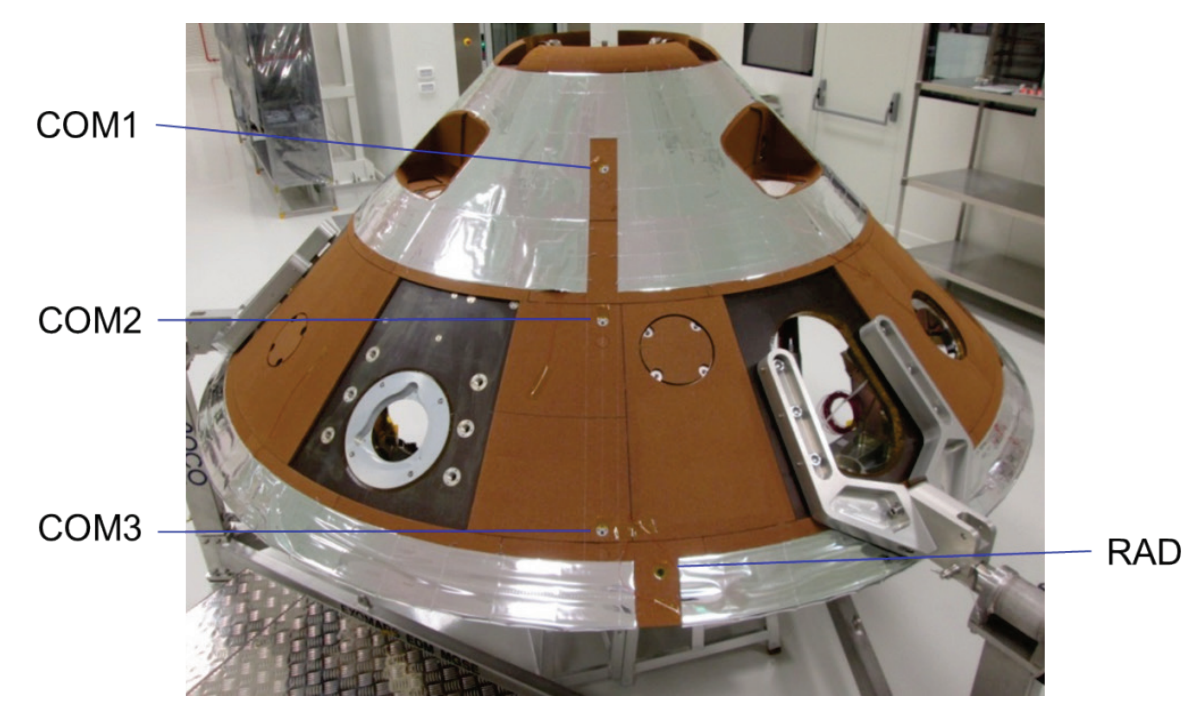

Figure 1: COMARS+ sensors integrated in the back cover of Schiaparelli.

The COMARS sensors and the broadband radiometer are fixed to the ExoMars back cover structure using honeycomb inserts to which the sensors are screwed with four M4 screws each. Figure 2 shows exterior and interior views of the COMARS sensor with denomination of the different parts. 

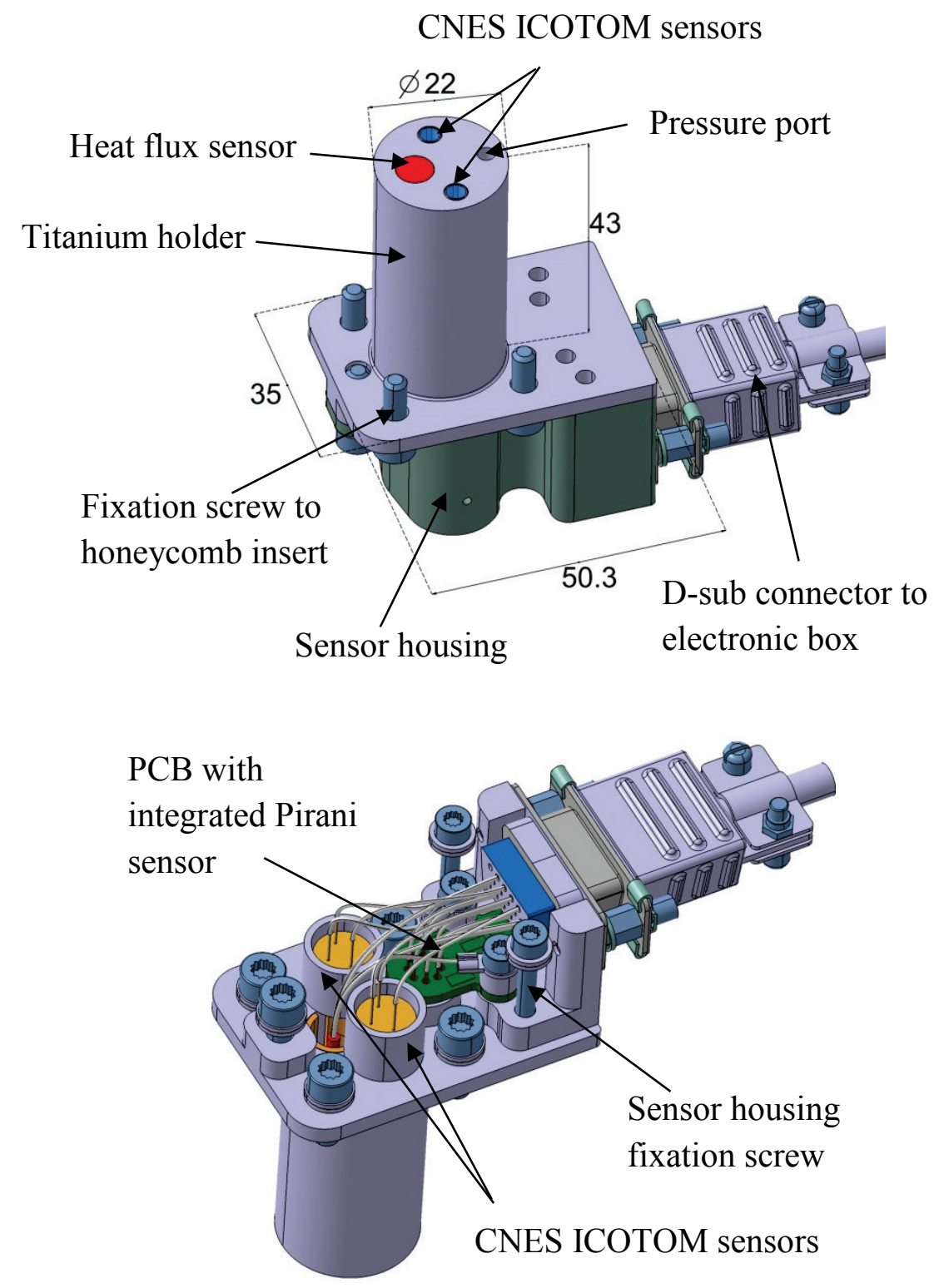

Figure 2: COMARS sensor assembly top view with dimensions [mm] (top) and rear surface view with removed sensor housing (bottom).

The layout of the Multiplexing Signal Conditioner (MSC, COMARS+ electronic box) is shown in Figure 3. It consists of one multiplexing board and one power board mounted on top of each other in an aluminium housing. The multiplexing board contains amplifiers, filters and the multiplexing circuit for the sensor signals. The power board generates the necessary voltage levels from the unregulated bus of the EDM using a DC/DC converter. The sensor signal multiplexing is controlled via clock and synchronization signals from the EDM data handling system. 

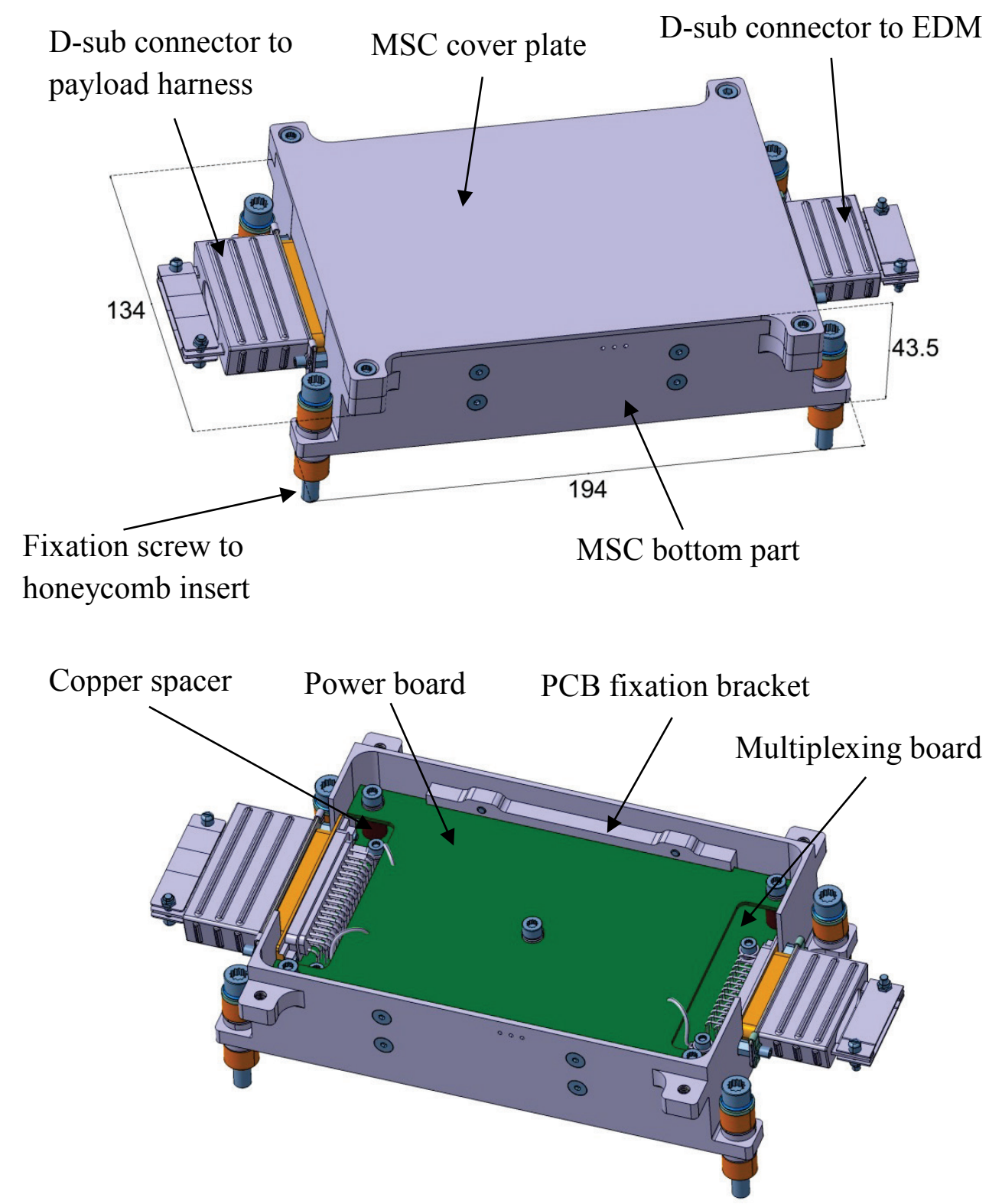

Figure 3: Electronic box of the COMARS+ payload external view with dimensions [mm] (top) and internal view (bottom). 


\section{STRUCTURAL ANALYSES}

To verify the structural integrity of the COMARS + components during the launch phase several structural analyses were performed. The electronic box is the heaviest part of the payload with a weight of 920 gram (with margins) and is therefore exposed to the highest mechanical stresses acting on box structure and fixation screws. In the following some results of the numerical analysis for the electronic box are shown. To evaluate the worst case vibration loads during launch and ascent, the qualification random vibration spectra for the electronic box is used (Figure 4). These random loads are converted into equivalent static loads using the Miles-equation. To do a worst case analysis the amplification factor for the Miles equation is set to $Q=16$. This is the maximum value measured on the electronic box bottom part during the qualification test campaign resonance search on all three axes. For the simulation this value is used for in-plane and outof-plane direction.
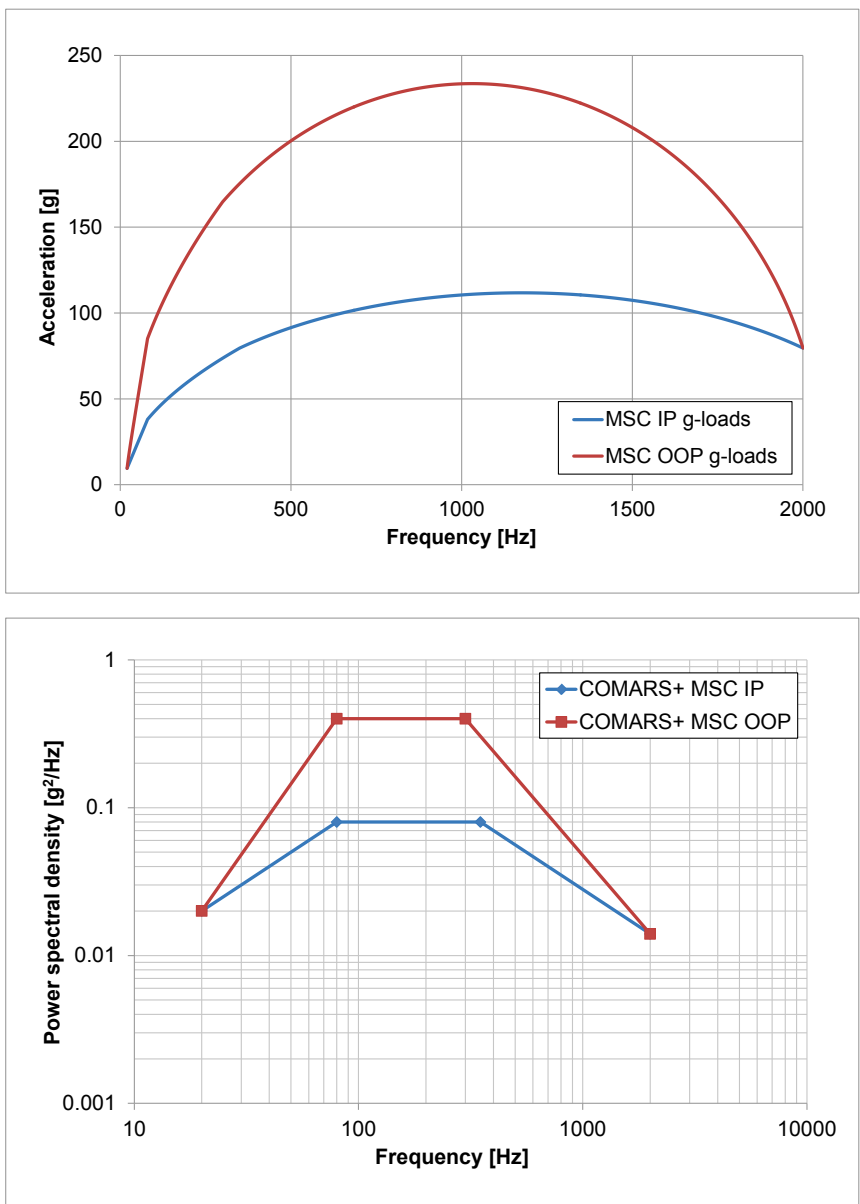

Figure 4: COMARS+ electronic box static load curve (upper figure) derived from random vibration loads (lower figure). 
In Figure 4 a static load curve is plotted for the complete frequency range between $20-2000 \mathrm{~Hz}$. For the worst case structural analysis the maximum values of $233 \mathrm{~g}$ (out-of-plane) and $111 \mathrm{~g}$ (in-plane) are used not taking into account the box natural frequency.

For the FEM-model some simplifications are made with respect to detailed interfaces, screws and PCB boards, but the overall mass of the box is kept constant. Figure 5 shows the resulting von Mises equivalent stress for the electronic box bottom part. The maximum stress value of $106 \mathrm{MPa}$ occurring at the mounting feet is thereby well below the yield strength of the used aluminium material $(380 \mathrm{MPa})$. The calculated stresses for the fixation components (screws, spacers, thermal washers) are also well inside the corresponding material stress limits.

In addition to the structural analyses modal analyses were also performed for sensors and electronic box to determine the first fundamental frequencies. The results show, that all fundamental frequencies are above the limit frequency of $140 \mathrm{~Hz}$ specified in the ExoMars mechanical interface requirements.

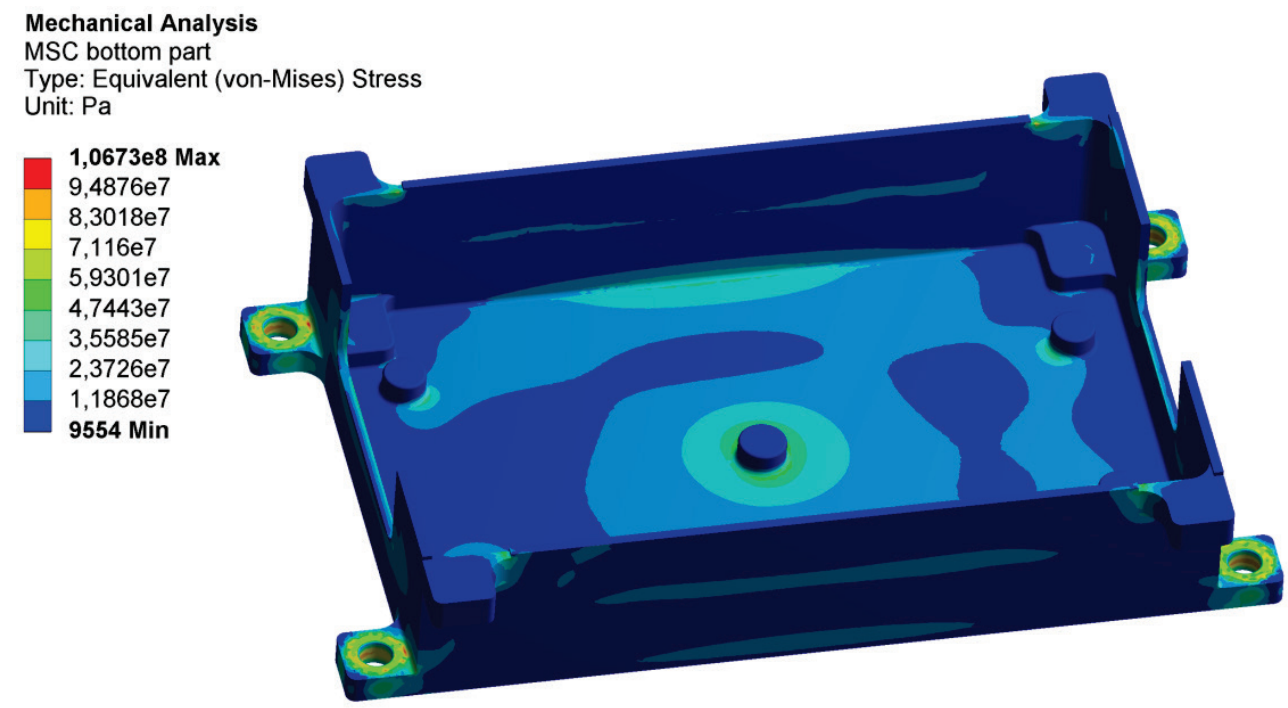

Figure 5: von Mises equivalent stress for box bottom part.

To determine the maximum deflection of the PCBs inside the electronic box a Power Spectral Density (PSD) analysis was performed using the random vibration loads shown in Figure 4 and a scaling factor of 3 Sigma. Figure 6 shows the deflection of multiplexing and power board perpendicular to the board plane. The maximum deflection of the multiplexing board occurs around the center. As a 
fixation screw is placed in the center of the PCB, the deflection is very small with a maximum of $0.2 \mathrm{~mm}$ which is well inside the tolerable range. The maximum deflection of the power board is larger with a maximum of $1.0 \mathrm{~mm}$ at the short sides. This is because the power board is not fixed to the electronic box structure by D-Sub connectors at these sides. As the components on the power board (DC/DC converter, voltage filter) are placed around the center of the PCB, where the deflections are lower, and are additionally fixed with epoxy adhesive, the larger deflection of the power board is not an issue.
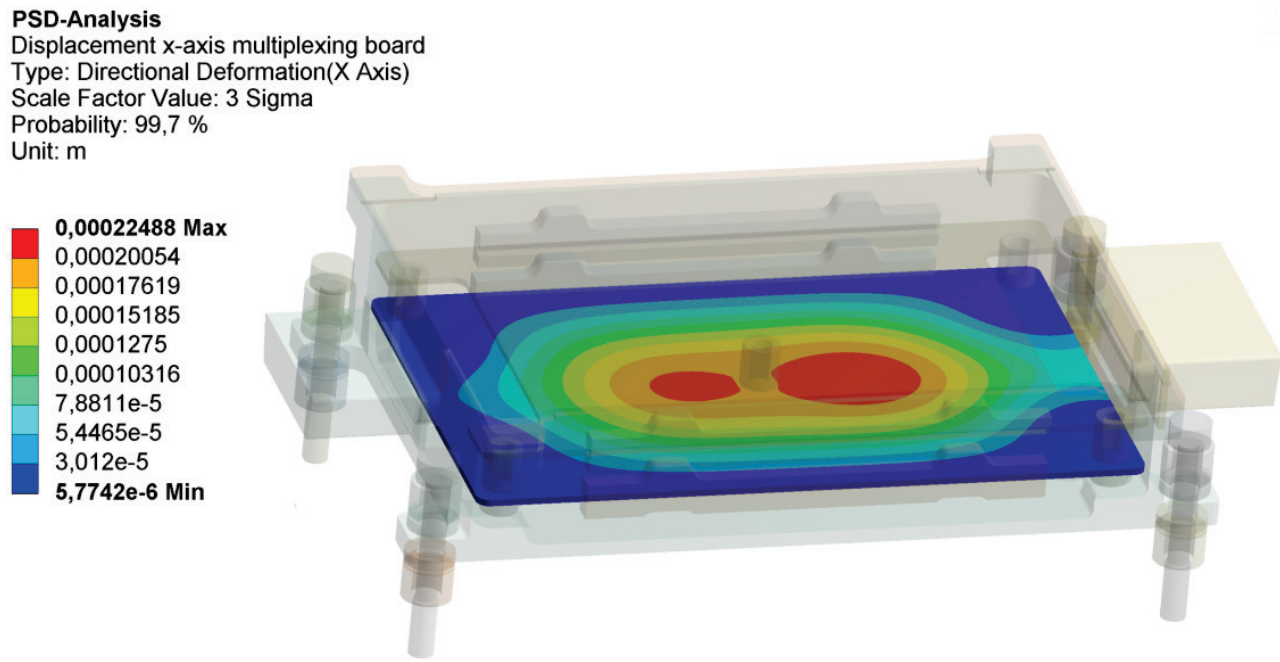

PSD-Analysis

Displacement $\mathrm{X}$-axis power board

Type: Directional Deformation(X Axis)

Scale Factor Value: 3 Sigma

Probability: 99,7\%

Unit: $\mathrm{m}$

0,001023 Max

0,00090996

0,00090996

0,00068397

0,00057097

0,00045798

0,00034498

0,00023199

0,00011899

5,9934e-6 Min

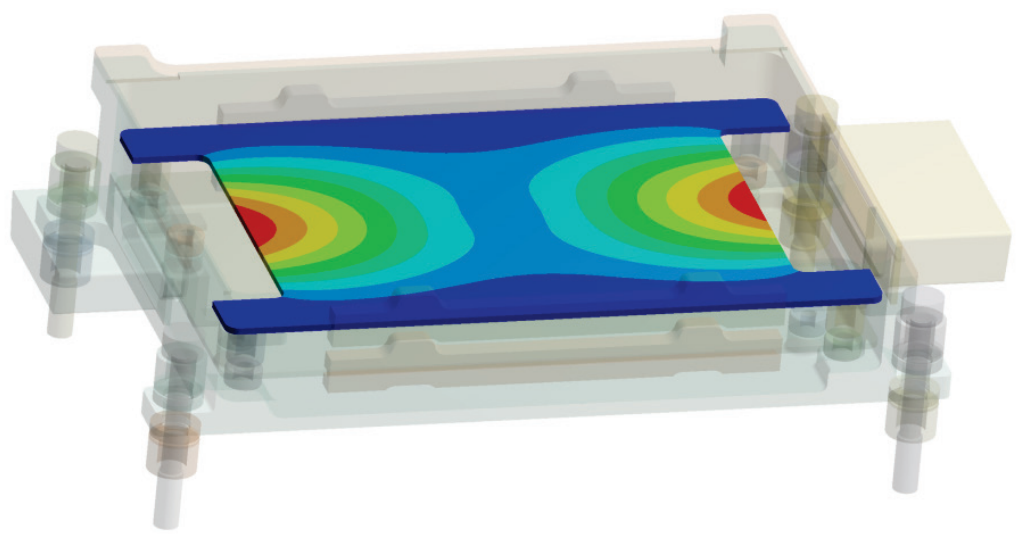

Figure 6: PSD analysis for electronic box, deflection of multiplexing board (upper figure) and power board (lower figure). 


\section{THERMAL ANALYSES}

To verify the temperature resistance of the COMARS sensor assembly during Mars entry transient thermal analyses were performed. The used thermal model consists of a cut-out of TPS and honeycomb structure with integrated COMARS sensor. The honeycomb structure is thereby modelled as a solid structure with adjusted material properties (density, thermal conductivity, specific heat capacity). For the COMARS sensor some simplifications are made for the thermal model. The honeycomb fixation screws, the sensor housing and the D-Sub connector are neglected, as these parts are located at the back end of the sensor and do not influence the heat conduction from the TPS to the lower parts of the sensor. Furthermore the Pirani pressure sensor and the ICOTOM detectors are not incorporated in the thermal model as their thermal properties and inner layout are unknown. Because these parts are also located at the sensor back end, their influence on the thermal analysis is insignificant. To evaluate the temperatures of Pirani pressure sensor and ICOTOM detectors, the temperature of the corresponding contact surface on the titanium holder is calculated (see also Figure 2 ). For the overall thermal model all contacts between the different parts are assumed to be bonded contacts.

The heat flux used for the thermal simulation can be seen in Figure 7 and is taken from the ExoMars EDM aerothermodynamic database. The COMARS and broadband radiometer sensors are thereby located in zones V and VI according to Figure 7. 

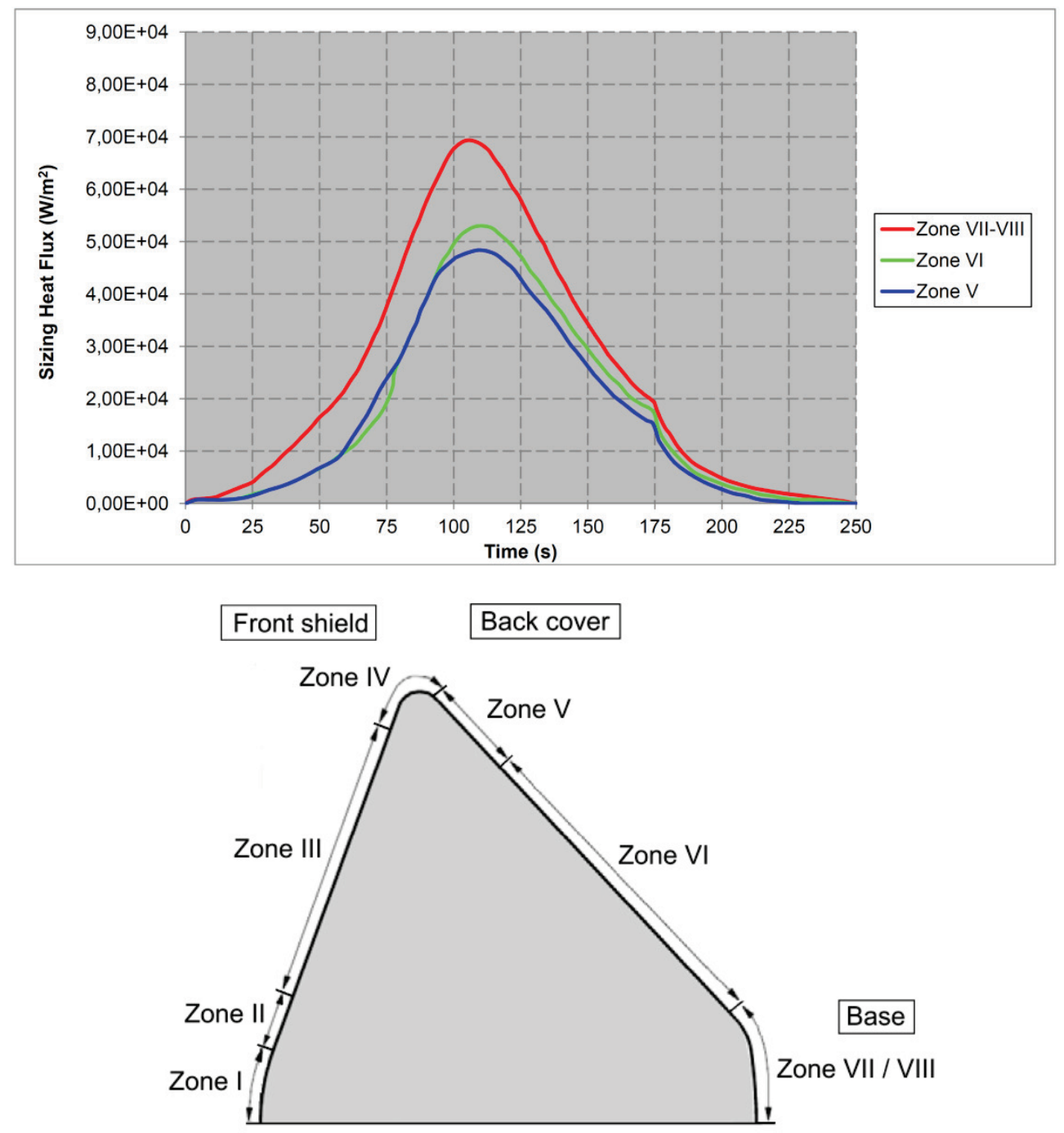

Figure 7: Sizing heat flux profile for EDM back cover TPS (upper figure) and EDM zone definition (lower figure), taken from ExoMars EDM aerothermodynamic database.

The shown heat flux profiles were computed with a wall temperature of $300 \mathrm{~K}$ and represent the worst-case heat fluxes to the TPS (sizing case). As the heat flux in zone VI is slightly higher than in zone V, the heat flux of zone VI is used for the thermal simulations.

The heat flux according to Figure 7 is applied to the upper TPS surface including the COMARS sensor surface. To simulate further heat conduction into the material after the heat flux becomes zero (at $\mathrm{t}=250 \mathrm{~s})$, the simulation time is extended to 450 seconds. A radiation to ambient space with an emissivity of 0.9 is assumed for the TPS surface. All other outer surfaces are set to be adiabatic. A uniform starting temperature of $300 \mathrm{~K}$ is used for the simulation to be compliant with the wall temperature assumption used for the heat flux calculation. 
In Figure 8 the temperature distribution inside the sensor is shown at the end of the simulation with a nearly homogeneous temperature of about $72^{\circ} \mathrm{C}$.

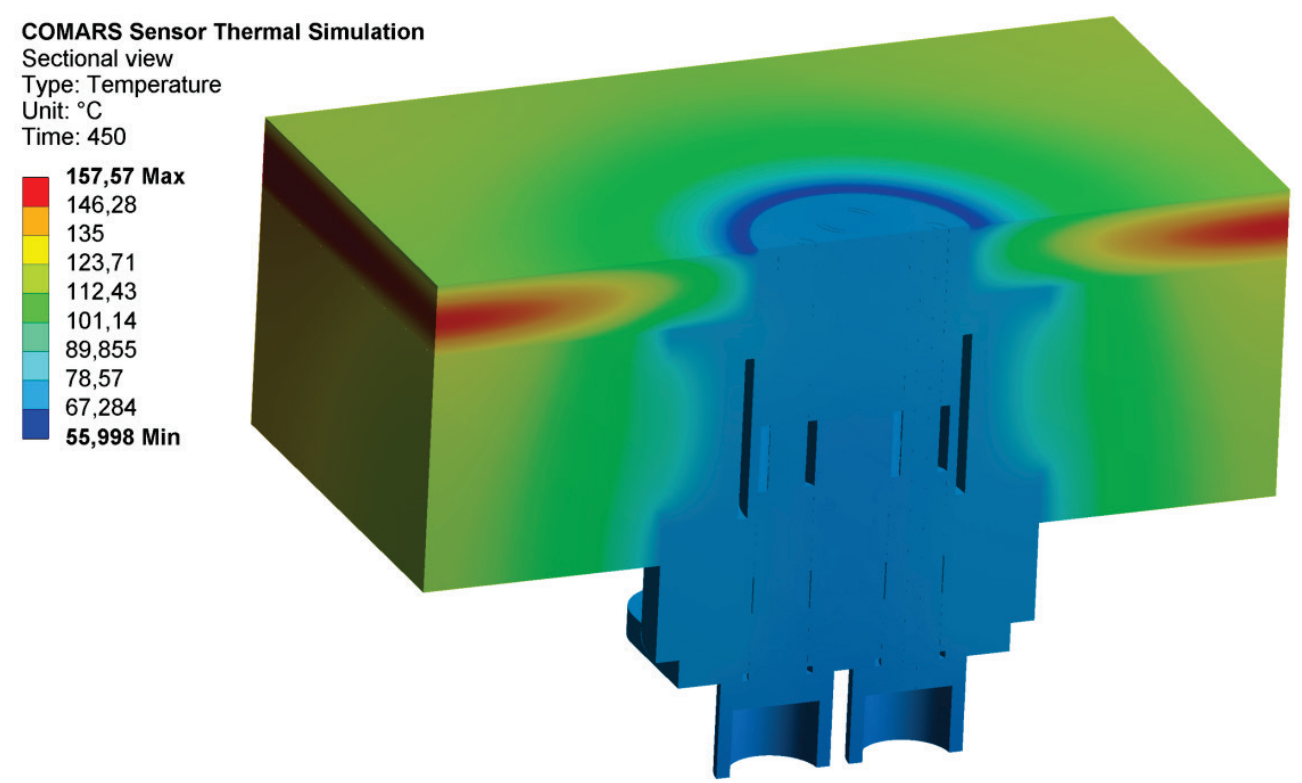

Figure 8: Computed temperature distribution at simulation end.

The resulting maximum temperatures of the different parts are presented in Figure 9. The COMARS titanium holder reaches a maximum temperature of $126^{\circ} \mathrm{C}$ at the sensor front end (TPS side) whereas the contact surfaces for Pirani and ICOTOM sensors only heat up to a maximum of $72^{\circ} \mathrm{C}$. As already shown in Figure 8, all sensor parts are at a nearly homogeneous temperature level at the end of the simulation time.

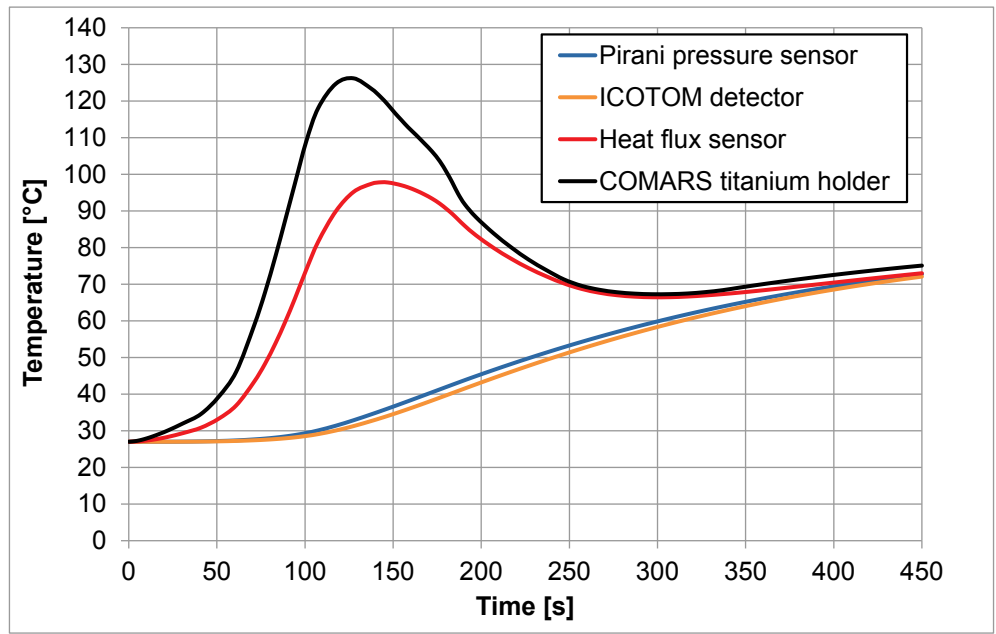

Figure 9: COMARS sensor thermal simulation maximum temperatures. 
In the following table the calculated temperatures of the COMARS sensor parts are summarized and compared with the corresponding maximum operative range. The EDM back cover separation takes place around $t=320$ s which is the end of the sensor measurement. Therefore the maximum temperatures before this time point are used for comparison to the maximum operative temperatures. As presented in the table all calculated values are inside the operative range which ensures that the COMARS sensor is capable to withstand the thermal environment during Mars entry.

Table 2: Calculated temperatures compared with maximum operative temperatures for the different COMARS sensor parts

\begin{tabular}{|l|l|l|}
\hline Part / contact surface & $\begin{array}{l}\text { Maximum } \\
\text { calculated } \\
\text { temperature } \\
\text { between } \mathrm{t}=0 \mathrm{~s} \text { and } \\
\mathrm{t}=320 \mathrm{~s}\left[{ }^{\circ} \mathrm{C}\right]\end{array}$ & $\begin{array}{l}\text { Maximum } \\
\text { operative } \\
\text { temperature }\left[{ }^{\circ} \mathrm{C}\right]\end{array}$ \\
\hline Pirani pressure sensor & 62 & 90 \\
\hline ICOTOM detector & 60 & 75 \\
\hline Heat flux sensor & 98 & 200 \\
\hline $\begin{array}{l}\text { COMARS titanium } \\
\text { holder }\end{array}$ & 126 & 400 \\
\hline
\end{tabular}

The calculated temperatures in Table 2 thereby represent worst-case temperatures and the actual values during Mars entry are expected to be lower because of the following reasons:

1. The starting temperature of the different parts will be lower than $300 \mathrm{~K}$ at the beginning of Mars entry leading to lower temperatures at the end of the measurement time.

2. The used assumption of bonded contacts between the different parts (perfect heat conduction) leads to higher sensor temperatures.

3. The used heat flux profile taken from the ExoMars EDM aerothermodynamic database represents the back cover TPS sizing case and therefore includes a safety margin.

To verify that the implementation of the COMARS sensor into the TPS will not lead to local overheating of TPS or honeycomb structure, a further simulation was performed only for the TPS structure using the same heat flux levels presented in 
Figure 7. A comparison of TPS and honeycomb structure temperatures with and without COMARS sensor is shown in Figure 10. The curves show the maximum temperatures of the lower TPS surface (intersection to the honeycomb) and of the lower side of the honeycomb structure (inner side of back cover). As shown in the figure, the maximum temperatures are lower for the case with a COMARS sensor due to a local heat sink effect. Therefore the integration of the COMARS sensor into the TPS does not cause local overheating of TPS or honeycomb structure. The same is true for the broadband radiometer.

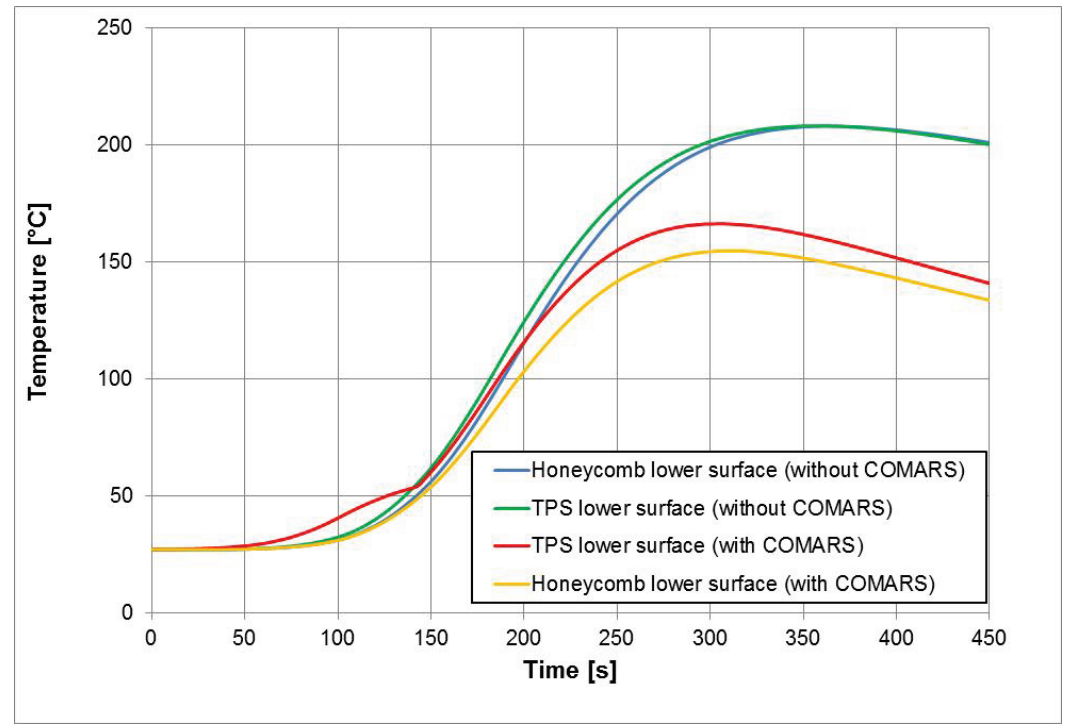

Figure 10: TPS maximum temperatures with and without COMARS sensor.

Another critical parameter is the temperature of the electronic box components during the long cruise phase. Therefore a transient thermal simulation was performed for the electronic box using conductive and radiative heat sink temperatures (thermal environment inside the EDM) provided by Thales Alenia Space Italy (TAS-I).

A homogeneous starting temperature of $-38^{\circ} \mathrm{C}$ and an adaptive time stepping with a maximum time step of 4000 seconds are used for the simulation. The calculated minimum and maximum temperatures for the PCBs inside the electronic box (multiplexing and power board) are shown in Figure 11. The identical maximum and minimum temperatures indicate that the box is in temperature equilibrium nearly the complete time. The only deviation occurs at the end of the calculation after the EDL entry point where the Mars entry takes place. At that time, beside the temperature rise due to Mars entry, the box is in its operational state 
dissipating energy. Because of this transient temperature environment the maximum and minimum temperatures are no longer identical.

Although the calculations show that the box temperatures remain well above the minimum non-operative / operative temperatures of about $-55^{\circ} \mathrm{C}$, TAS-I installed a heater foil on the box casing to heat up the box in case of need.

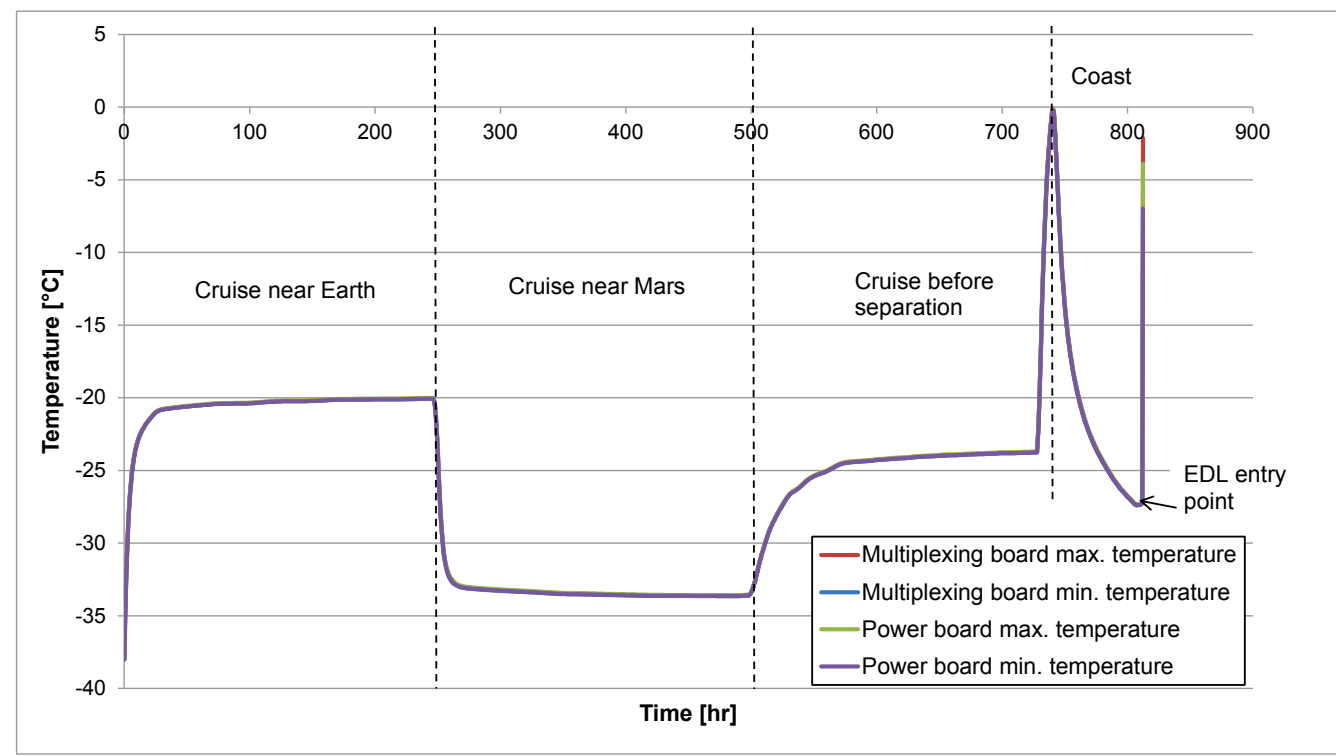

Figure 11: Electronic box PCBs maximum and minimum temperatures during ExoMars flight. 


\section{QUALIFICATION AND ACCEPTANCE TESTS AND BIOBURDEN REDUCTION}

The structural and thermal simulations described in the last two sections were performed as worst case analyses. No verification of the simulation results was performed by tests as the applied mechanical and thermal loads are well oversized, in addition to the simplified boundary conditions which also represent "oversized" assumptions. Therefore the effect of inaccurate numerical modeling can be neglected for these worst case analyses. The actual design verification was done by extensive qualification and acceptance test campaigns. These tests included:

1. Vibration and shock tests to simulate all mechanical loads that occur during flight, like launch loads and stage separation shocks.

2. Thermal cycling tests under vacuum condition to simulate the thermal environment of the capsule.

3. Electromagnetic compatibility (EMC) tests to check that the payload is compatible with the electromagnetic environment of the capsule and does not emit electromagnetic energy that could cause electromagnetic interference in other devices.

4. Radiation tests for the COMARS+ sensors to verify their radiation hardness.

5. Bioburden reduction and analyses to show the compliance with the planetary protection requirements.

For the qualification tests a set of COMARS+ components was manufactured. These components had to pass all environmental tests listed above. Although the verification of the planetary protection requirements is not necessary for the qualification models, it was necessary to test the cleaning and bioburden reduction approach before applying it on the flight hardware.

All qualification tests were performed successfully without any failures or malfunctions. Therefore no design updates were necessary between qualification and flight model. The flight and flight spare models were qualified according to 
the acceptance test procedures incorporating mechanical, thermal/vacuum and electromagnetic compatibility tests at acceptance level.

The upper image of Figure 12 shows the flight model of the electronic box mounted to the shaker for the out-of-plane random vibration test including attached accelerometers for shaker control (control 1 and control 2) and resonance search (MSC-Top-XYZ and MSC-Side-XYZ).
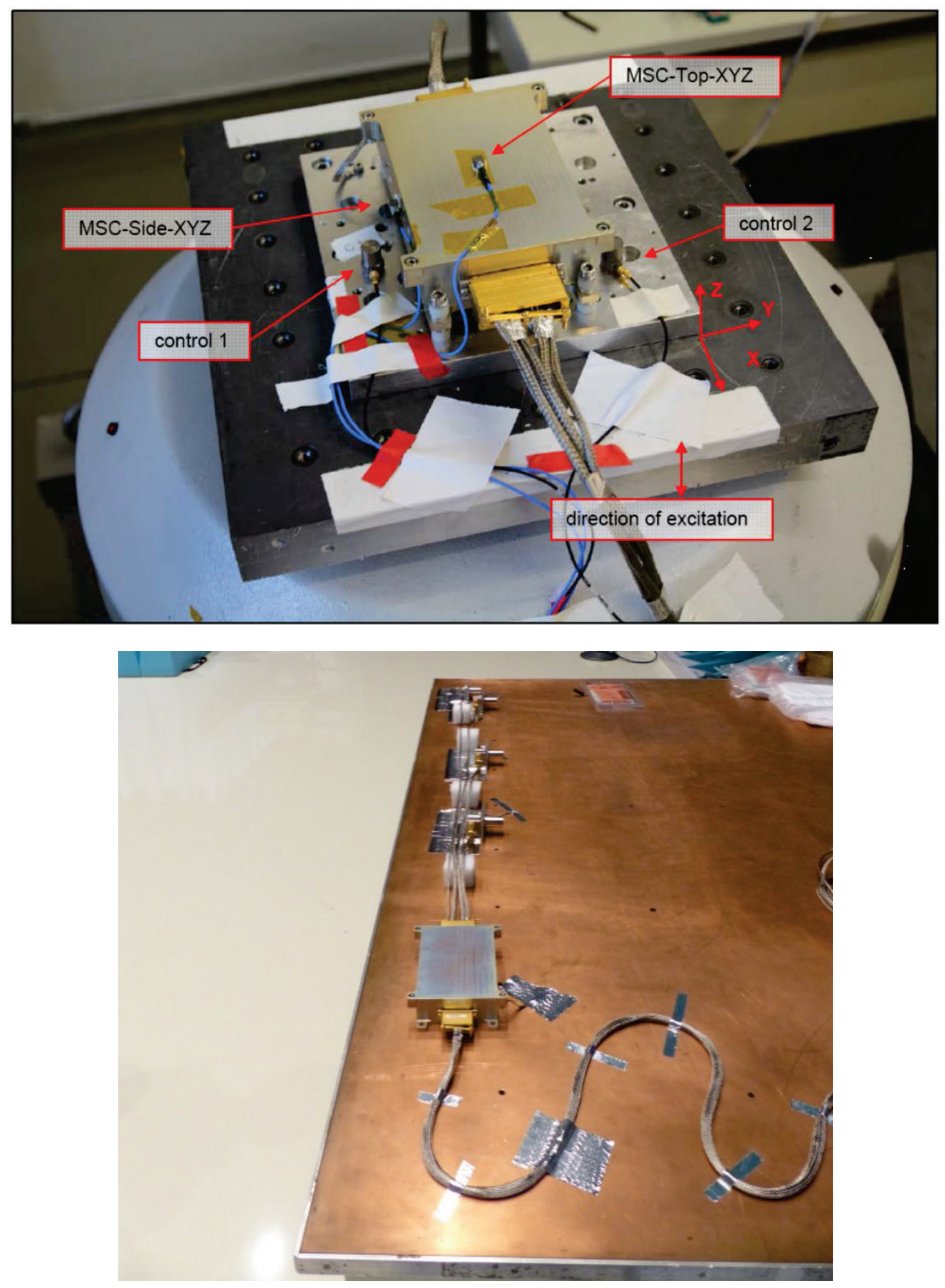

Figure 12: Shaker test for electronic box in out-of-plane direction (upper figure) and COMARS+ payload mounted to copper table during EMC tests (lower figure).

For this test the overall $g_{\text {rms }}$ level was 10.4. On the lower image of Figure 12 the COMARS+ payload is shown mounted to a copper table during EMC tests for radiated susceptibility. The overall EMC tests furthermore included radiated emission, conducted emission and conducted susceptibility tests. To verify the 
power requirements, the payload inrush current was measured in addition to the payload power consumption and susceptibility to variations in the supply voltage. Bonding and isolation measurements for electronic box and sensors were also part of the EMC test campaign. On the upper image of Figure 13 the thermocouple attachment for the thermal vacuum test is shown for the four COMARS sensors (three flight and one spare model). The sensors are mounted to an adapter which in turn is mounted to a temperature controlled plate inside a vacuum chamber. The thermocouple temperatures are used to verify that the required temperature levels are reached during the test. The diagram on the lower image of Figure 13 shows two recorded temperature cycles with test temperatures between $-105^{\circ} \mathrm{C}$ and $67^{\circ} \mathrm{C}$ for the COMARS sensors.
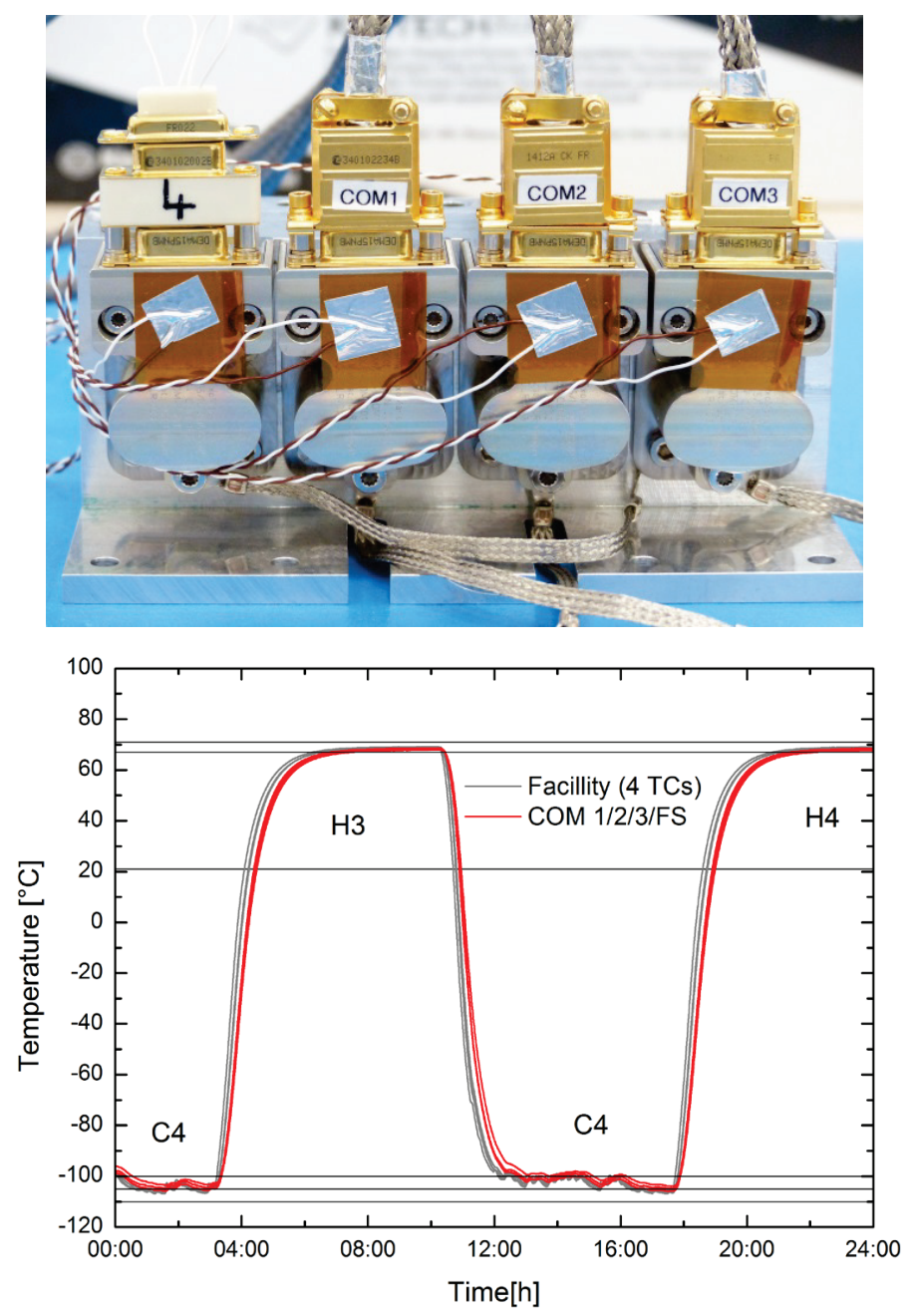

Figure 13: Preparation of COMARS sensors for thermal vacuum test (upper figure) and recorded temperature cycles of sensors COMARS 1, 2, 3 and flight spare in comparison to the facility temperatures (lower figure). 
To satisfy the requirements concerning planetary protection all flight and flight spare model components and the necessary assembly tools were cleaned thoroughly with Isopropanol before assembly using sterile wipes and an ultrasonic cleaner filled with Isopropanol. Cleaning and assembly were carried out in an ISO 5 laminar flow bench. Afterwards all acceptance tests for the payload parts were conducted in a clean room environment of ISO 8. After successful completion of the tests, all accessible surfaces were again cleaned with Isopropanol. In the final step all payload components were subjected to Dry Heat Microbial Reduction (DHMR) at $122^{\circ} \mathrm{C}$ for 126 minutes (harness) and 166 minutes (other payload components). The temperature and time periods correspond to a 3-log surface bioburden reduction for the harness cables and a 2-log mated bioburden reduction for the payload components. After DHMR the payload components were brought to a highly controlled ISO 1 clean room for a final functional check. The resulting bioburden of the COMARS+ payload was verified by several bioburden assays taken before the DHMR process and after the final functional test. Overall 22 samples were taken prior to DHMR and 9 samples after the functional test. All assays showed no colony forming units after $72 \mathrm{~h}$ of incubation which satisfied the corresponding requirements for surface bioburden. Because the applied conditions for temperature and time during the DHMR process did not reduce the encapsulated bioburden of the COMARS+ hardware, the number of encapsulated spores was evaluated using bioburden level estimates for flight hardware according to the planetary protection requirements document. Considering the complete volume of the non-metallic payload components, the overall number of encapsulated spores amounts to 7096 which also satisfied the corresponding requirement.

After the final functional test and the verification of the planetary protection requirements the payload components were packed in sterile bags and sent to TAS-I for integration into the Schiaparelli capsule. 


\section{AEROTHERMAL TESTS}

Aerothermal tests were performed in the L2K facility of the Supersonic and Hypersonic Technology Department of DLR Cologne [17]. For the final aerothermal tests a representative wedge configuration with integrated qualification models was used (Figure 14). This configuration is similar to the flight case. As during the actual Mars entry, the sensors are directly exposed to boundary layer flow and radiation coming from the shock layer. The COMARS sensor and the broadband radiometer were integrated into the wind tunnel model at the same distance from the model holder nose tip to guarantee the same flow condition on both sensors. The test conditions were chosen in such a way, that the concentration of the $\mathrm{CO}_{2}$ molecules, i.e. radiative heating, could be varied significantly. The enthalpy was varied from $5.6 \mathrm{MJ} / \mathrm{kg}$ to $9.2 \mathrm{MJ} / \mathrm{kg}$ leading to a $\mathrm{CO}_{2}$ mole fraction change from 0.546 to 0.227 .

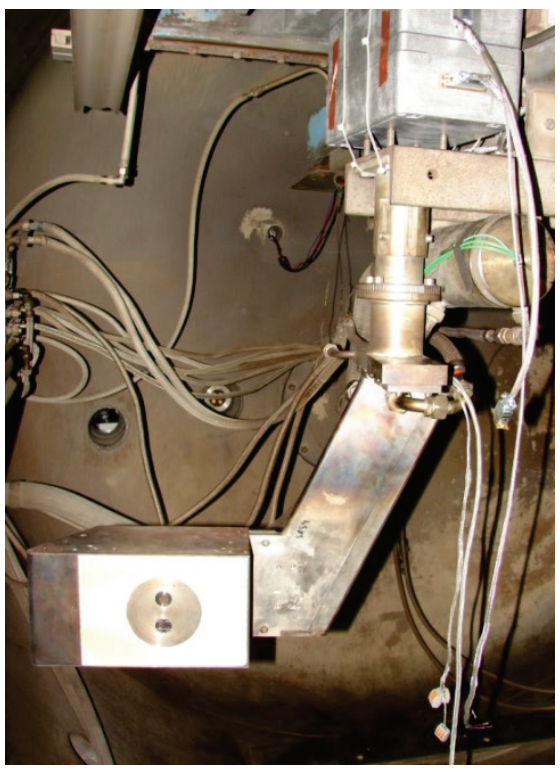

\begin{tabular}{|c|c|c|}
\hline Test condition & low enthalpy & high enthalpy \\
\hline gas mass flow rate $[\mathrm{g} / \mathrm{s}]$ & 41.2 & 41.2 \\
\hline reservoir pressure $[\mathrm{hPa}]$ & 790 & 930 \\
\hline specific enthalpy $[\mathrm{MJ} / \mathrm{kg}]$ & 5.6 & 9.2 \\
\hline total temperature $[\mathrm{K}]$ & 2815 & 3283 \\
\hline nozzle throat/exit diameter [mm] & $29 / 200$ & $29 / 200$ \\
\hline distance from nozzle exit [mm] & 250 & 250 \\
\hline distance from nozzle throat $[\mathrm{mm}]$ & 654 & 654 \\
\hline free stream static pressure $p_{1}[\mathrm{hPa}]$ & 0.5 & 0.4 \\
\hline free stream static temperature $T_{1}[K]$ & 744 & 604 \\
\hline free stream density $\rho_{1}\left[\mathrm{~kg} / \mathrm{m}^{3}\right]$ & $2.7 \cdot 10^{-4}$ & $2.5 \cdot 10^{-4}$ \\
\hline free stream velocity $v_{1}[\mathrm{~m} / \mathrm{s}]$ & 2306 & 2611 \\
\hline mole fraction of $\mathrm{CO}_{2} \quad[-]$ & 0.546 & 0.227 \\
\hline mole fraction of $\mathrm{CO}$ & 0.277 & 0.459 \\
\hline mass fraction of $\mathrm{O}_{2}$ & 0.122 & 0.162 \\
\hline mass fraction of $\mathrm{O}$ & 0.027 & 0.126 \\
\hline mass fraction of $\mathrm{N}_{2}$ & 0.022 & 0.016 \\
\hline mass fraction of $\mathrm{NO}$ & 0.005 & 0.009 \\
\hline
\end{tabular}

Figure 14: COMARS and broadband radiometer sensors integrated in a flat plate model in the L2K facility (left) and test flow parameters (right).

Figure 15 shows the measured surface pressure of the COMARS sensor in comparison with the test chamber pressure. Since the model injection into the flow leads to an increase in the test chamber pressure, this data is a very good indicator for the model position. The surface pressure measured with the COMARS sensor increases, when the model is moved into the flow around 
$\mathrm{t}=108 \mathrm{~s}$ at low enthalpy flow condition. After a short exposure time (approx. 8 seconds) the model is moved out of the flow and the flow parameters are tuned for the high enthalpy condition. At this condition the model is injected into the flow at $\mathrm{t}=232 \mathrm{~s}$. After a short exposure time it is removed from the flow again. In order to check the repeatability of the sensor data the flow parameters are changed back to the low enthalpy case and the model is moved into the flow at $t=290 \mathrm{~s}$. As shown in the figure the repeatability of the data is very good.
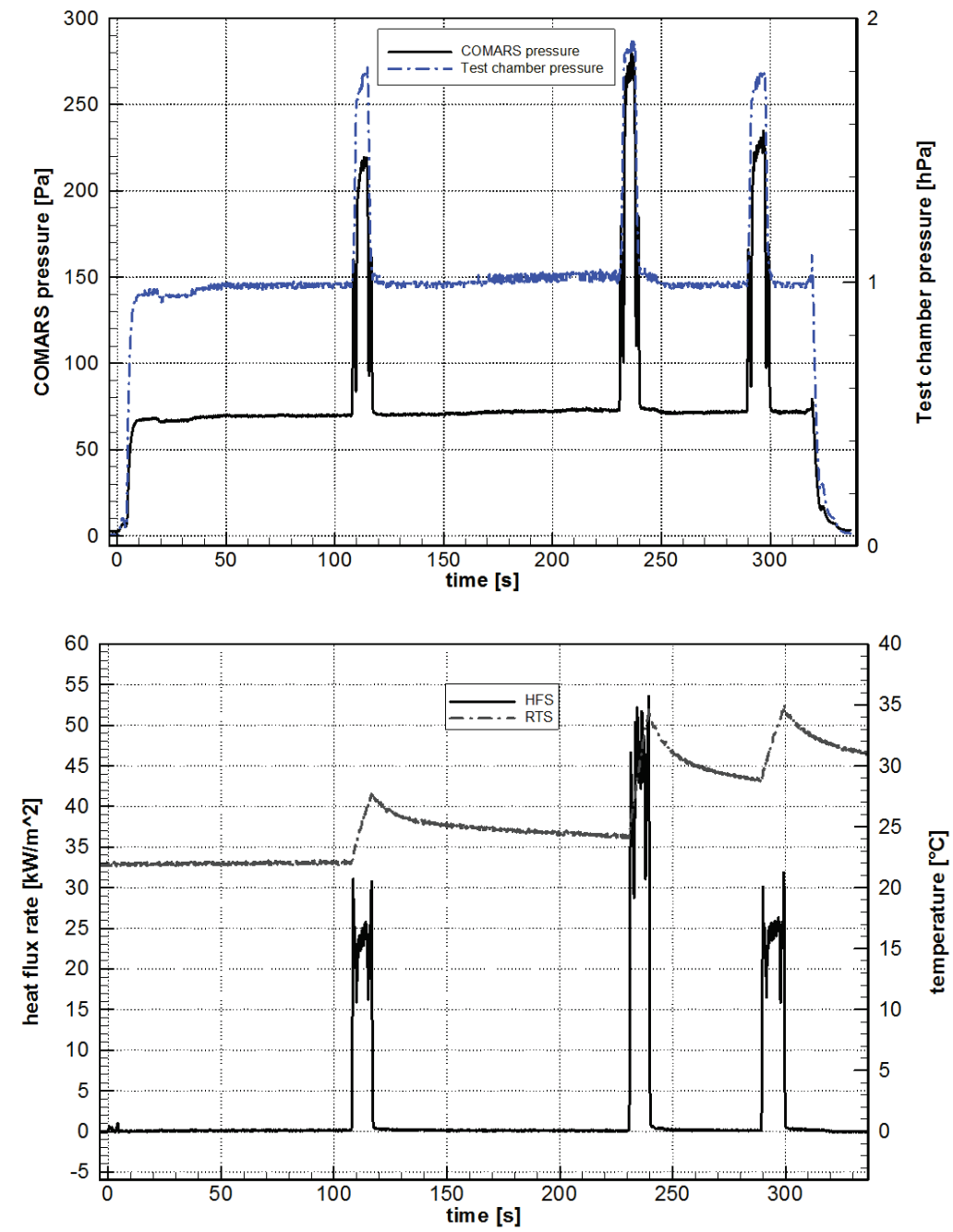

Figure 15: Measured pressure (upper figure) and total heat flux rate (HFS) including sensor surface temperature (RTS) (lower figure) at two different flow conditions.

The measured total heat flux is presented on the lower image of Figure 15. The HFS curve represents the heat flux and the RTS curve represents the surface temperature of the sensor. The data is in excellent correlation with the pressure data. Because of the very fast response time of approx. 300 microseconds the heat flux sensor also resolves the heat flux peaks when the model passes through the 
side shocks of the free stream flow caused by its injection and removal from the flow field. At the low enthalpy condition the sensor measures a heat flux rate of $25 \mathrm{~kW} / \mathrm{m}^{2}$ on the flow axis. For the high enthalpy test case this value increases to approximately $45 \mathrm{~kW} / \mathrm{m}^{2}$. As shown in the figure the repeatability of the measurement is again very good. The situation for the radiative heat flux is different (Figure 16). The radiometer measures the radiative heat flux even without being inside the flow. Therefore the data up to 83 seconds represents the radiation of the free stream at low enthalpy condition. After that the facility parameters electrical current and mass flow rate are varied to reach the high enthalpy flow condition which is achieved at $\mathrm{t}=150 \mathrm{~s}$. Compared to the low enthalpy case the radiative heat flux is lower which is related to the lower $\mathrm{CO}_{2}$ concentration at high enthalpy condition. This is in contrast to the total heat flux which is mainly convective. The model is injected into the flow at $\mathrm{t}=175 \mathrm{~s}$. Due to the model leading edge shock the flow density increases and leads to higher radiation compared to the free stream case. After the model is removed from the flow the low enthalpy flow parameters are set again. In the low enthalpy condition the injection of the model into the flow at $\mathrm{t}=221 \mathrm{~s}$ only causes a slight increase in the measured radiative heat flux.

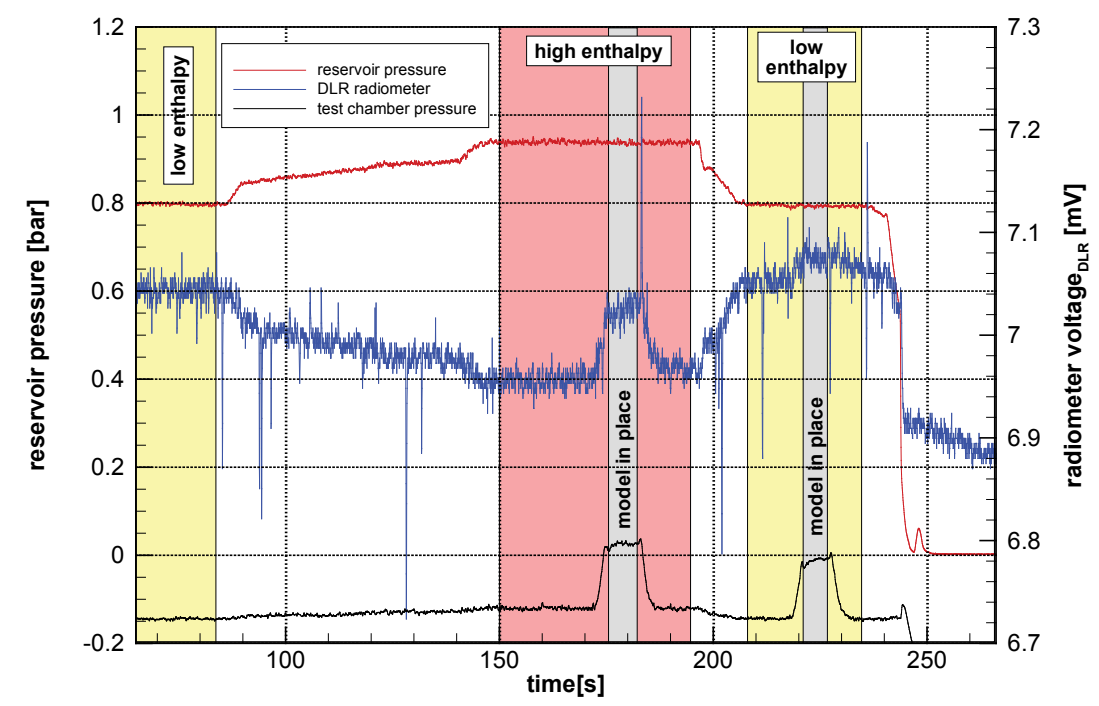

Figure 16: Measured radiative heat flux by the broadband radiometer at two different flow conditions.

Complementary to the radiometer measurements the IR-spectrum of the flow was measured with a Fourier Transformed Infrared Spectrometer (FTIR). The idea was 
to identify the main species which contribute to radiation over a broad spectral range between 1 and $16 \mu \mathrm{m}$. The upper image of Figure 17 shows the measured infrared spectrum during the tests in the $\mathrm{L} 2 \mathrm{~K}$ facility. The radiation in the range of the $4.3 \mu \mathrm{m}$ band (wavenumber of $2300 \mathrm{~cm}^{-1}$ ) is very dominant. In the spectral range shown in the diagram there are also lines of excited $\mathrm{CO}$ molecules which are clearly visible. For a clear identification of the $\mathrm{CO}$ contribution the emission spectra of $\mathrm{CO}$ for predicted free stream temperatures were computed for low and high enthalpy conditions. The lower image of Figure 17 shows the comparison between measured low enthalpy flow spectrum and computed $\mathrm{CO}$ spectrum for $900 \mathrm{~K}$.
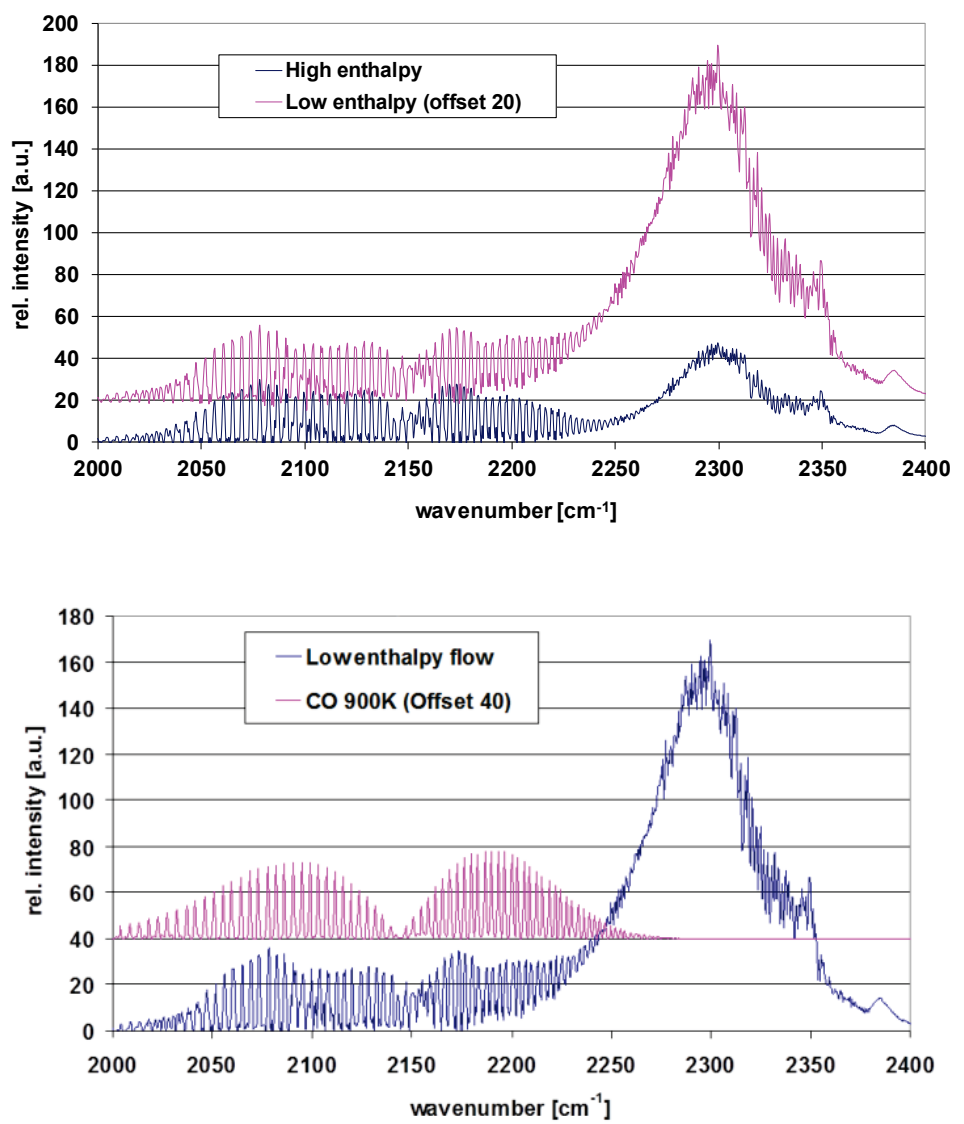

Figure 17: Measured spectra at both flow conditions (upper figure) and comparison to calculated spectrum for $\mathrm{CO}$ (lower figure). 


\section{CONCLUDING REMARKS}

In order to measure aerothermal parameters on the back cover of the ExoMars Schiaparelli lander the instrumentation package COMARS + was developed by DLR. Consisting of three combined aerothermal sensors, one broadband radiometer sensor and an electronic box the payload provided important data for future missions. This data could be used for adapting TPS design margins and for reconstruction of Martian atmospheric parameters.

The aerothermal sensors called COMARS combine four discrete sensors measuring static pressure, total heat flux, temperature and radiative heat flux at two specific spectral bands. The infrared radiation in a broadband spectral range is measured by the separate broadband radiometer sensor. The electronic box of the payload is used for amplification, conditioning and multiplexing of the sensor signals. The ambitious low mass and low power design ended with a total mass of $1.73 \mathrm{~kg}$ and a power consumption of $4.5 \mathrm{Watt}$ for the complete payload. After COMARS + passed all qualification and acceptance tests it was integrated into the Schiaparelli capsule in January 2015 at the ExoMars integration site at Thales Alenia Space in Turin.

Although the landing of Schiaparelli failed, a part of the flight data during the entry phase was transmitted to the TGO at low sampling rate. All COMARS+ sensors delivered useful data with respect to total heat flux rate, radiative heat flux rate, surface temperature and surface pressure of Schiaparelli from the Martian entry point until parachute deployment with the exception of the plasma black-out phase. Since measured structure and sensor housing temperature are far below predicted pre-flight values, a new calibration using spare sensors at temperatures below $0^{\circ}$ is necessary. This requires implementation of a black body source into the vacuum chamber. After the completion of the new calibration COMARS+ flight data will be analyzed and published.

\section{ACKNOWLEDGEMENTS}

The authors express their special acknowledgement to the European Space Agency (ESA) and Thales Alenia Space Italy for their support. 


\section{REFERENCES}

[1] Ingoldby, R. N., Michel, F. C., Flaherty, T. M., Doryand, M. G., Preston, B.; Villyard, K. W., and Steele, R. D., "Entry Data Analysis for Viking Landers 1 and 2 Final Report", NASA CR-159388, Martian Marietta Corporation, Nov. 1976.

[2] Karl T. Edquist, Michael J. Wright, Giary A. Allen Jr., "Viking Afterbody Heating Computations and Comparisons to Flight Data", $44^{\text {th }}$ AIAA Aerospace Sciences Meeting and Exhibit, 9-12 January 2006, Reno, Nevada, USA.

[3] Frank S. Milos, "Galileo Probe Heat Shield Ablation Experiment", Journal of Spacecraft and Rockets, Vol. 34, No. 6, November-December 2017.

[4] Frank S. Milos, Y. K. Chen, William M. Congdon and Janine M. Thorton, "Mars Pathfinder Entry Temperature Data, Aerothermal Heating, and Heatshield Material Response", Journal of Spacecraft and Rockets, Vol. 36, No. 3, May-June 1999.

[5] Edquist, K. T., Dyakonov, A. A., Wright, M. J., and Tang, C. Y., “Aerothermodynamic Design of the Mars Science Laboratory Heatshield", AIAA Paper 2009-4075, June 2009.

[6] Wright, M. J., Beck, R. A. S., Edquist, K. T., Driver, D. M., Sepka, S. A., Slimko, E. M., Willcockson, W. H., DeCaro, A., and Hwang, H. H., "Sizing and Margins Assessment of the Mars Science Laboratory Aeroshell Thermal Protection System", AIAA Paper 20094231, June 2009.

[7] Munk, M., Little, A., Kuhl, C., Bose, D., and Santos, J., "Mars Science Laboratory (MSL) Entry, Decent and Landing Instrumentation (MEDLI) Hardware", 23rd AAS/AIAA Spaceflight Mechanics Meeting, American Astronomical Soc. Paper 2013-310, Feb. 2013.

[8] Bose, D., White, T., Santos, J. A., Feldman, J., Mahzari, M., Olson, M., and Laub, B., "Initial Assessment of Mars Science Laboratory Heatshield Instrumentation and Flight Data", AIAA Paper 2013-0908, Jan. 2013.

[9] Bose, D., White, Mahzari, M., and Edquist, K. T., "Reconstruction of Aerothermal Environment and Heat Shield Response of Mars Science Laboratory", Journal of Spacecraft and Rockets, Vol. 51, No. 5, July-August 2014.

[10] Karlgaard,C. D.,Kutty, P., Schoenenberger, M., Schidner, J., and Munk, M., "Mars Entry Atmospheric Data System Trajectory Reconstruction Algorithms and Flight Results", AIAA Paper 2013-0028, Jan. 2013.

[11] Mark Schoenenberger, John Van Norman, Chris Karlgaard, Prasad Kutty, and David Way, "Assessment of the Reconstructed Aerodynamics of Mars Science Laboratory Entry Vehicle", Journal of Spacecraft and Rockets, 2014, Vol.51: No. 4, July-August 2014.

[12] S. Portigliott, et. Al., "EXOMARS 2016, the Schiaparelli Mission, EDL Demonstration Results from Real Time Telemetry before Unfortunate Impact", 14th International Planetary Probes Workshop, IPPW-2017-271.

[13] Michael J. Wright, Frank S. Milos and Philippe Tran," Afterbody Aeroheating Flight Data for Planetary Probe Thermal Protection System Design", Journal of Spacecraft and Rockets, Vol. 43, No. 5, September-October 2006.

[14] Th. Eggers, J.M.A. Longo et al., "The SHEFEX Flight Experiment - Pathfinder Experiment for a Sky Based Test Facility", Proceedings AIAA $14^{\text {th }}$ Spaceplane Systems and Technologies Conference, Canberra, Australia, November 2006.

[15] Gülhan, F. Siebe, T. Thiele, D. Neeb, J. Turner, J. Ettl, "Challenges of the SHEFEX-II Flight Instrumentation and Selected Flight Data", Journal of Spacecraft and Rockets, Vol. 51, No. 1 (2014), pp. 175-186.

[16] Gülhan, A., Thiele, T., Siebe, F., "Combined Sensor Assembly COMARS+ for ExoMars EDM Demonstrator", 7th European Workshop on Thermal Protection Systems and Hot Structures, ESA ESTEC, Noordwijk, April 2013.

[17] Gülhan, B. Esser, "Arc-Heated Facilities as a Tool to Study Aerothermodynamic Problems of Re-entry Vehicles", in: F. K. Lu, D. E. Marren: Advanced Hypersonic Test Facilities, Progress in Astronautics and Aeronautics, Vol. 198, pp. 375-403, AIAA, 2002. 


\section{List of Figures}

Figure 1: COMARS+ sensors integrated in the back cover of Schiaparelli.......... 11

Figure 2: COMARS sensor assembly top view with dimensions [mm] (top) and rear surface view with removed sensor housing (bottom).

Figure 3: Electronic box of the COMARS + payload external view with dimensions $[\mathrm{mm}]$ (top) and internal view (bottom).

Figure 4: COMARS+ electronic box static load curve (upper figure) derived from random vibration loads (lower figure) ............................................................. 14

Figure 5: von Mises equivalent stress for box bottom part. ................................ 15 Figure 6: PSD analysis for electronic box, deflection of multiplexing board (upper figure) and power board (lower figure). 16

Figure 7: Sizing heat flux profile for EDM back cover TPS (upper figure) and EDM zone definition (lower figure), taken from ExoMars EDM aerothermodynamic database.

Figure 8: Computed temperature distribution at simulation end.......................... 19

Figure 9: COMARS sensor thermal simulation maximum temperatures. ............. 19

Figure 10: TPS maximum temperatures with and without COMARS sensor. ..... 21

Figure 11: Electronic box PCBs maximum and minimum temperatures during ExoMars flight.

Figure 12: Shaker test for electronic box in out-of-plane direction (upper figure) and COMARS+ payload mounted to copper table during EMC tests (lower figure).

Figure 13: Preparation of COMARS sensors for thermal vacuum test (upper figure) and recorded temperature cycles of sensors COMARS 1, 2, 3 and flight spare in comparison to the facility temperatures (lower figure).

Figure 14: COMARS and broadband radiometer sensors integrated in a flat plate model in the L2K facility (left) and test flow parameters (right).

Figure 15: Measured pressure (upper figure) and total heat flux rate (HFS) including sensor surface temperature (RTS) (lower figure) at two different flow conditions.

Figure 16: Measured radiative heat flux by the broadband radiometer at two different flow conditions.

Figure 17: Measured spectra at both flow conditions (upper figure) and comparison to calculated spectrum for $\mathrm{CO}$ (lower figure). 


\section{List of Tables}

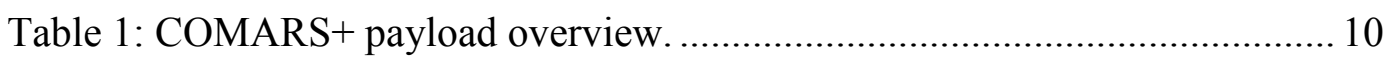

Table 2: Calculated temperatures compared with maximum operative temperatures for the different COMARS sensor parts ....... 